[Agr. Biol. Chem., Vol. 36, No. 9, p. 1603 1609, 1972]

\title{
The Increase of Indophenol Reducing Value of Boiled Potato $(3)^{\dagger}$
}

\author{
By Shinji Numa \\ Department of Agricultural Chemistry, Faculty of Agriculture, \\ Yamaguchi University, Yamaguchi \\ Received January 19, 1972
}

\begin{abstract}
The contribution of the system of DOPA, tyrosine and polyphenol oxidase to the remarkable increase of indophenol reducing value during the boiling procedure of the aqueous extract of potato was investigated and discussed. When the red solution of resulting DOPAchrome by the action of polyphenol oxidase on DOPA and tyrosine at the level of potato juice was heated, the solution turned from red to colorless and simultaneously the indophenol reducing value increased remarkably. And it seems that the resulting indophenol reducing substance is a sort of reductone, 5,6-dihydroxyindole. The system of other polyphenols gave little increase of indophenol reducing value. Therefore the system of DOPA, tryosine and polyphenol oxidase is specific to the above increase.
\end{abstract}

The indophenol reducing value increases during the boiling procedure of aqueous or acid extract of potato tubers. In the previous papers $^{1,2)}$ it was reported that this was not due to the formation of L-ascorbic acid (ASA) resulted by the heat degradation of the bound form of ASA, but to the formation of reductones by the heat degradation of dehydroL-ascorbic acid (DHA), and that aminocarbonyl reaction between DHA or sugars and amino acids did not contribute to the increase of the indophenol reducing value of boiled extract of potato. However, it was not enough to explain the above phenomenon only with the formation of reductones by the heat degradation of DHA, because the scale of the increase of the indophenol reducing value of the boiled solution of DHA, whose concentration was in rough accord with that of potato extract, was smaller than that of potato extract. So, it was needed to find ano-

\footnotetext{
Formation of Indophenol Reducing Substances by Heat Treatment of Some Plant Tissue Extracts. Part III.*2)

${ }^{* 2)}$ Part II: see reference 2).
}

ther factor to explain sufficiently the increase of the indophenol reducing value of boiled potato extract.

In further studies, the author used the old potato having a high activity of indophenol reduction, in spite of the low concentration of DHA, and found out that an intermediate produced by the action of polyphenoloxidase on 3,4-dihydroxyphenylalanine (DOPA) and tyrosine gave a high indophenol reducing value by heating. The contribution of the system of DOPA, tyrosine and polyphenol oxidase to the increase of indophenol reducing value during the boiling procedure of the aqueous extract of potato is described in this paper.

\section{MATERIALS AND METHODS}

Potatoes. Potatoes (mainly Danshaku) were obtained commercially, stored at room temperature until the tubers germinated and began to wither. These potatoes were used as old potatoes throughout the present study.

Aqueous extract of potatoes. Potato tubers were washed with water, peeled, homogenized in a mixer 
for $3 \mathrm{~min}$ with 4 volumes of water, and filtered through a cotton cloth. The filtrate was centrifuged at $27,000 \mathrm{G}$ for $30 \mathrm{~min}$. The reddish supernatant was finally diluted 5 volumes with water.

Assay for indophenol reducing value. The method of indophenol-xylene was used and its assay procedure was the same as described in the previous paper ${ }^{11}$ for the assay procedure of vitamin $\mathrm{C}$. The indophenol reducing value was expressed as $\mathrm{mg} \%$ of ASA.

Reagents. Aqueous DHA solution was prepared by the oxidation of aqueous ASA solution with ethereal $p^{\text {-benzoquinone solution. }}{ }^{3)}$ All other chemicals were of analytical reagent grade.

Determination of DHA. DHA content was determined by the 2,4-dinitrophenylhydrazine method as described previously. ${ }^{13}$

Determination of DOPA and tyrosine. The contents of DOPA and tyrosine were determined according to the method of Arnow."

Preparation of polyphenol oxidase solution. Polyphenol oxidase solution was prepared for example as follows: $95 \mathrm{~g}$ of peeled potato tubers was homogenized in a mixer for $3 \mathrm{~min}$ with $200 \mathrm{ml}$ of $0.05 \mathrm{M}$ phosphate buffer ( $\mathrm{pH} 6.0$ ), and filtered through a cotton cloth. The filtrate was centrifuged at $27,000 \mathrm{G}$ for $20 \mathrm{~min}$ in the cold. The reddish supernatant was treated with 2 volumes of cold acetone. The precipitate, collected by centrifugation $(5500 \mathrm{G} \times 20 \mathrm{~min})$, was suspended in $50 \mathrm{ml}$ of $0.05 \mathrm{M}$ phosphate buffer ( $\mathrm{pH} 6.0$ ), and precipitated by addition of ammonium sulphate to $80 \%$ saturation. The centrifuged precipitate was suspended in a minimal volume of the same buffer, and dialyzed against the same buffer overnight, and the dialyzate was centrifuged. The supernatant $(18.5 \mathrm{ml})$ was used as polyphenol oxidase solution in the present study, and in this case, $1 \mathrm{ml}$ of the enzyme solution corresponded to the amount of the enzyme in $5.1 \mathrm{~g}$ of potato tuber.

\section{RESULTS}

Heat treatment of potato juice of low $D H A$ content

As Fig. 1(A) shows, the aqueous extract of potatoes gave the remarkable increase of indophenol reducing value by heating, in spite of low DHA content. On the other hand, the

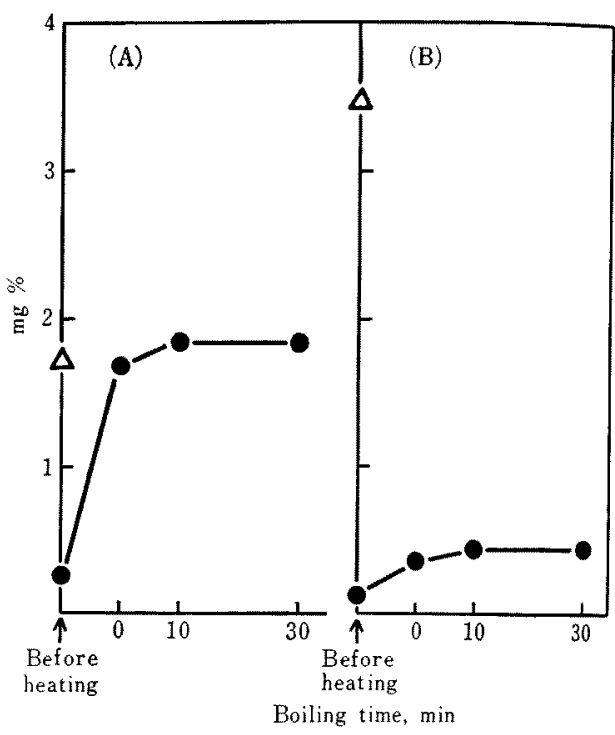

FIG. 1. Indophenol Reducing Values during Boiling Procedure.

(A) Potato juice of low DHA content.

(B) $3.5 \mathrm{mg} \%$ DHA in $0.1 \mathrm{~m}$ phosphate buffer (pH 6.0).

- Indophenol reducing value. $\triangle-\triangle D H A$ content.

DHA content of the extract of fresh potato was usually 3 to $3.5 \mathrm{mg} \%$, and the model solution of $3.5 \mathrm{mg} \%$ of DHA showed only the increase of $0.5 \mathrm{mg} \%$ in the indophenol reducing value as shown in Fig. 1 (B). These results indicate that the increase of indophenol reducing value of boiled potato juice is due to not only DHA but also some other substances.

\section{Stability of the precursor of the indophenol reducing substance}

The old potato juice was divided in two parts, and one part was kept at $5^{\circ} \mathrm{C}$ and the other at $30^{\circ} \mathrm{C}$ added with a few $\mathrm{ml}$ of toluene. Indophenol reducing values in both cases were determined at intervals after boiling for $5 \mathrm{~min}$. At $5^{\circ} \mathrm{C}$, the substance in question was relatively stable, and the indophenol reducing value increased till $24 \mathrm{hr}$ and then decreased gradual- 


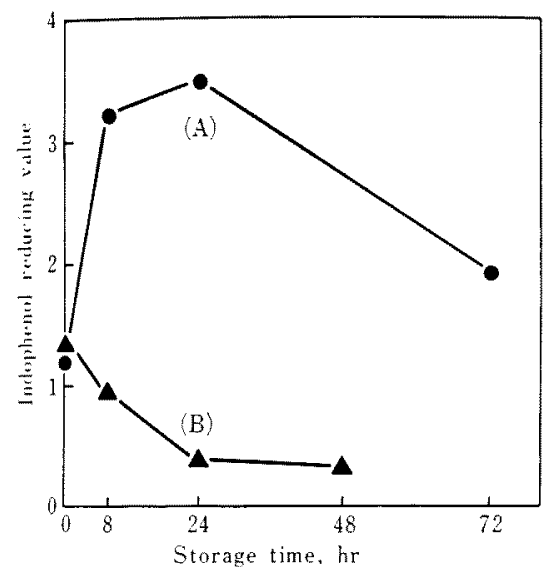

FIG. 2. Stability of the Precursor of the Indophenol Reducing Substance.

- Indophenol reducing value, stored at $5^{\circ} \mathrm{C}$.

- Indophenol reducing value, stored at $30^{\circ} \mathrm{C}$.

ly as shown in Fig. 2(A), whereas at $30^{\circ} \mathrm{C}$ it was unstable and the value quickly decreased as shown in Fig. 2(B). On the other hand, the sample under storage at $5^{\circ} \mathrm{C}$ was first reddish, and gradually turned reddish brown, and at the point of the highest indophenol reducing value it was dark brown or black. This indicates some correlation between the increase of indophenol reducing value and the formation of melanin.

\section{Stability of the indophenol reducing substance}

Potato juice was boiled for $5 \mathrm{~min}$ and divided in two parts. Each part was kept at $5^{\circ} \mathrm{C}$ and $30^{\circ} \mathrm{C}$, respectively, and each of indophenol reducing value was determined. The value decreased remarkably at both $5^{\circ} \mathrm{C}$ and $30^{\circ} \mathrm{C}$ as shown in Fig. 3. These results show that the indophenol reducing substance produced by heating of potato juice is very labile.

Gel filtration of the concentrate of potato juice

The aqueous extract $(82 \mathrm{ml})$, obtained from $57 \mathrm{~g}$ of old potato tubers, was concentrated to $12.6 \mathrm{ml}$ by lyophilization. The concentrate

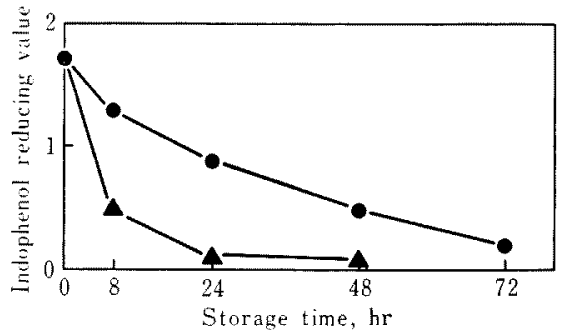

FIG. 3. Stability of the Indophenol Reducing Substance Produced by Heating of Potato Juice.

- Indophenol reducing value, stored at $5^{\circ} \mathrm{C}$.

$\Delta-\Delta$ Indophenol reducing value, stored at $30^{\circ} \mathrm{C}$.

$(11.6 \mathrm{ml})$ was subjected to gel filtration on a Sephadex G-10 column $(1.7 \times 85 \mathrm{~cm})$ equiliblated with water. Elution was performed with water at the rate of $12 \mathrm{ml}$ an hour in the cold. Each fraction was diluted 5 times, and the indophenol reducing value after heating and the DHA content were determined. Heating was done in a boiling water bath for

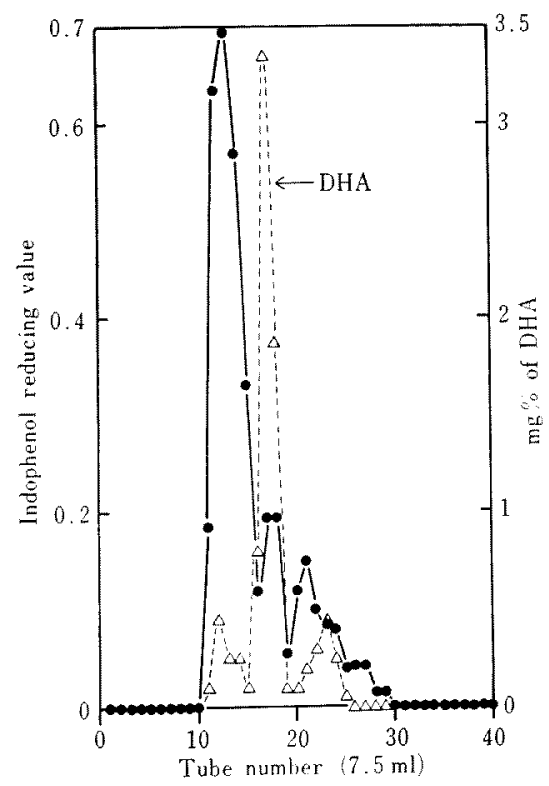

FIG. 4. Gel Filtration of the Concentrate of Potato Juice on a Sephadex G-10 Column $(1.7 \times 85 \mathrm{~cm})$.

- Indophenol reducing value. $\triangle--\triangle \mathrm{DHA}$ content. 
$5 \mathrm{~min}$. The first peak, the fraction of the highest indophenol reducing value, agreeded with the black pigment fractions of melanin, and was succesively separated from DHA fractions as shown in Fig. 4. This indicates a close correlation between the precursor of the indophenol reducing substance and the melanin formation process.

\section{$p H$ treatment of the gel filtrate fractions}

Each $3 \mathrm{ml}$ of the gel filtrate fractions (tube No. 12 15), the black pigment fractions of melanin, was added to $12 \mathrm{ml}$ of Walpole's acetate buffer ( $\mathrm{pH} 3.0$ ), water and Clark-Lubs' buffer (pH 9.0) respectively, and kept at $5^{\circ} \mathrm{C}$. After $43 \mathrm{hr}$, each of indophenol reducing value was determined after heat treatment. Since the black pigment precipitated at $\mathrm{pH} 3$, the precipitate was collected by centrifugation and suspended in $15 \mathrm{ml}$ of the same buffer, and the indophenol reducing values of the supernatant and the suspension were determined after heating. Table I shows that the indo-

Table I. pH Treatment of Sephadex G-10 Fraction

\begin{tabular}{cccc}
\hline pH of buffer & \multicolumn{2}{c}{$\begin{array}{c}\text { Indophenol reducing } \\
\text { value }\end{array}$} & Final pH \\
\hline 3.0 & sup. & 0.188 & 3.4 \\
& ppt. & 0.858 & \\
water & & 0.880 & 6.5 \\
9.0 & & 0.760 & 8.9 \\
\hline
\end{tabular}

phenol reducing value is almost in the precipitate fraction at $\mathrm{pH} 3$. These results indicate more strongly that the precursor of the indophenol reducing substance is closely related to the melanin formation process.

The system of DOPA, tyrosine and polyphenol oxidase

Many data in the present study indicate the correlation of the precursor of the indophenol reducing substance with the melanin formation process. Since it is well known in potatoes that the melanin is formed by the oxidation of tyrosine and DOPA by polyphenol oxidase, the model solution of DOPA, tyrosine and polyphenol oxidase at the level of potato juice was prepared, stored at $5^{\circ} \mathrm{C}$, and the indophenol reducing value was determined at intervals after heat treatment. The model solutions were as follows:

Sample 1; $1 \mathrm{mg}$ of DOPA, $1.5 \mathrm{mg}$ of tyrosine and $3.9 \mathrm{ml}$ of polyphenol oxidase solution.

Sample $2 ; 1.5 \mathrm{mg}$ of tyrosine and $3.9 \mathrm{ml}$ of the enzyme solution.

Sample $3 ; 1 \mathrm{mg}$ of DOPA and $3.9 \mathrm{ml}$ of the enzyme solution.

Each sample was diluted with $0.1 \mathrm{M}$ phosphate buffer ( $\mathrm{pH} 6.0$ ) to the total volume of $100 \mathrm{ml}$.

As Fig. 5 shows, the remarkable increase of indophenol reducing value after heating was obtained from sample 1 and 3 . Consequently it is clear that this remarkable increase was mainly due to the reaction between DOPA and its oxidase. And the result from sample 2 shows that the system of tyrosine and its oxidase also considerably contributed to the increase.

Comparison of the model solution (including

$D H A$ ) and potato juice at the level of fresh potato

The aqueous extract of fresh potato tubers was stored at $5^{\circ} \mathrm{C}$ and analyzed as shown in Fig. 6(A). According to these data, a model solution (including DHA) was prepared as follows and determined as shown in Fig. 6(B); $1 \mathrm{mg} \%$ of DOPA, $7 \mathrm{mg} \%$ of tyrosine and $3.5 \mathrm{mg} \%$ of DHA in $0.1 \mathrm{M}$ phosphate buffer (pH 6.0), and the corresponding amount of polyphenol oxidase to that in fresh potato extract.

The scale of the increase of indophenol reducing value was almost same in both cases. In the model system, however, maximum 


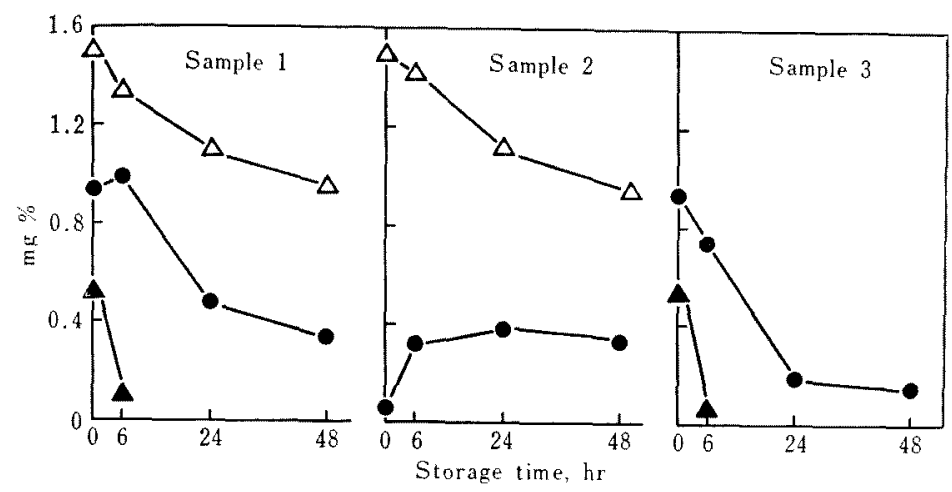

FIG. 5. Changes of the Indophenol Reducing Values and of the Amounts of Tyrosine and DOPA during the Storage of the Mixture of Tyrosine, DOPA and Polyphenol Oxidase at $5^{\circ} \mathrm{C}$.

- Indophenol reducing value.

$\triangle-\triangle$ DOPA content. $\triangle-\triangle$ Tyrosine content.

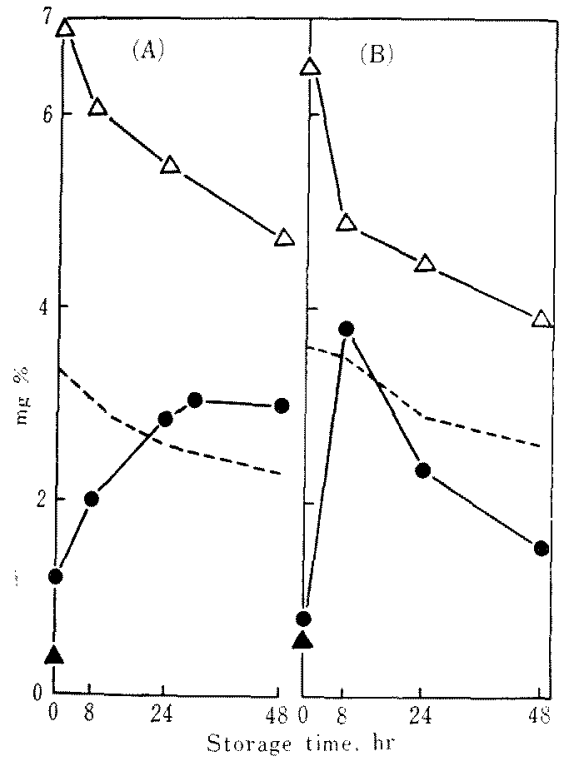

FIG. 6. Changes of Indophenol Reducing Values and of the Amounts of Tyrosine, DOPA and DHA.

- Indophenol reducing value. A $-\triangle$ DOPA content. $\triangle-\triangle$ Tyrosine content. -...- DHA content.

of indophenol reducing value was reached faster and its decline was quicker than in the case of potato extract. This may depend on the differences of the reaction rate of poly-

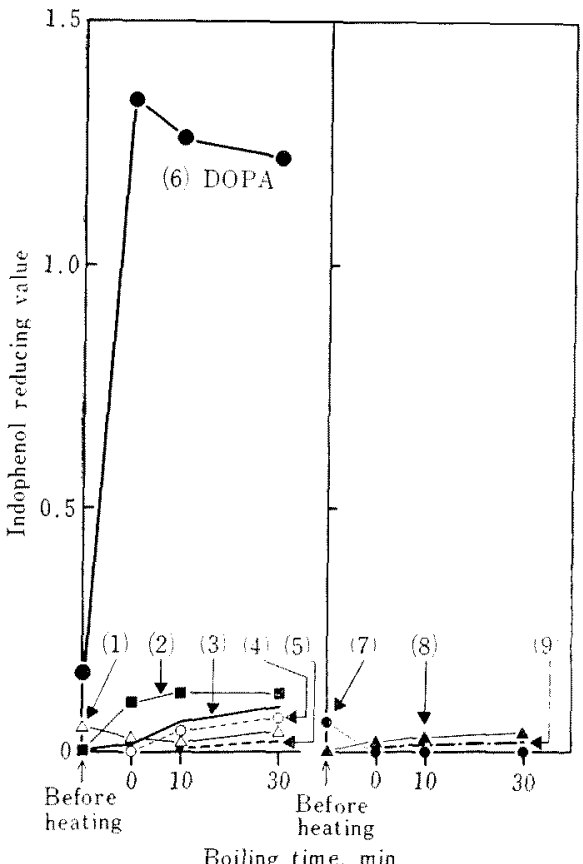

Fig. 7. Changes of the Indophenol Reducing Value in the Systems of Various Polyphenols and Polyphenol Oxidase.

(1) Quercetin, (2) Pyrogallol, (3) Catechol (4) Caffeic acid, (5) Chlorogenic acid, (6) DOPA, (7) Tyrosine, (8) p-Cresol, (9) p-Coumaric acid. 


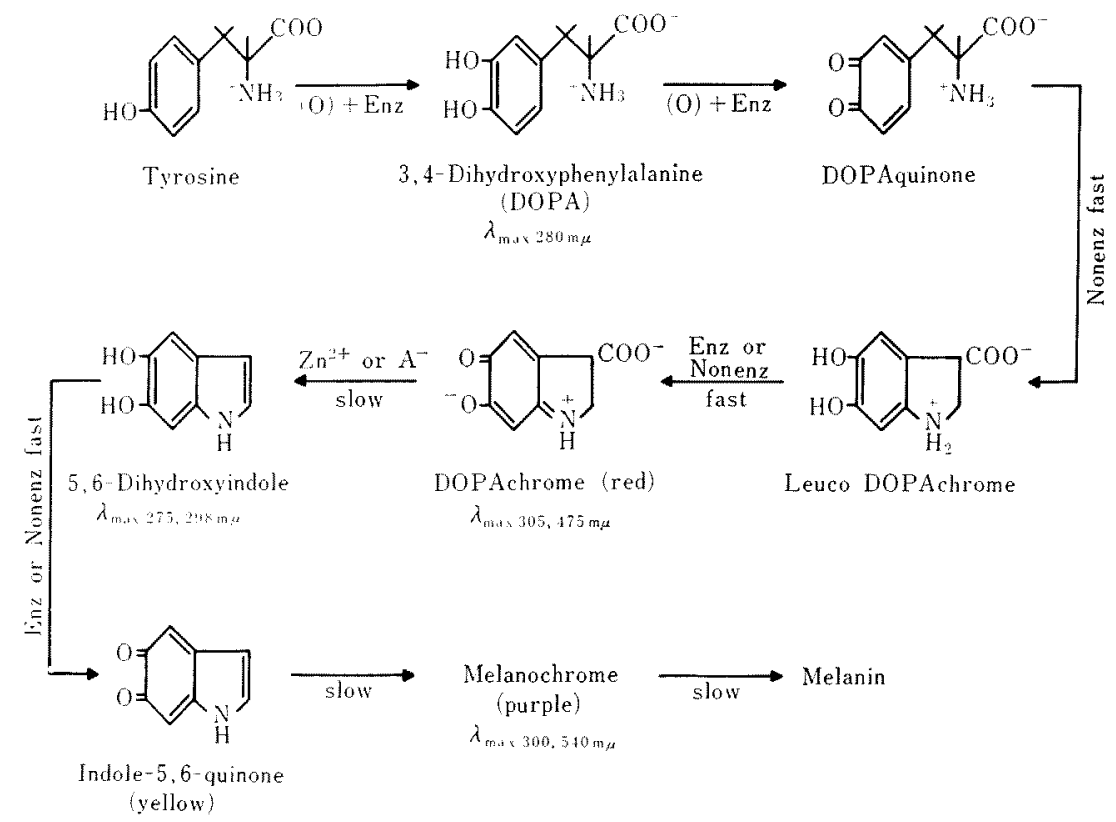

FIG. 8. Pathway of Melanin Formation by the Action of Polyphenol Oxidase on Tyrosine or DOPA. ${ }^{5 !}$

phenol oxidase on the substrates, and of the factors to stabilize the resulting products, in both solutions.

The systems of other polyphenols and polyphenol oxidase

The mixtures of other mono-, di- or triphenols and polyphenol oxidase in $0.1 \mathrm{M}$ phosphate buffer ( $\mathrm{pH}$ 6.0) were prepared and the indophenol reducing values were determined after heating. Phenols tested were chlorogenic acid, catechol, quercetin, caffeic acid, pyrogallol, $p$-cresol and p-coumaric acid, and DOPA and tyrosine were used as standard. The concentration of each phenol was $10^{-4}$ $M$ for convenience. This value roughly accorded with that of DOPA in potato juice ( $2 \mathrm{mg} \%$ ). As Fig. 7 shows, the increase of indophenol reducing value was only little in each system except for the system of DOPA which showed great increase. The system of tyrosine did not give any increase. This may be due to the lag period ${ }^{5}$ for hydroxylation of tyrosine to DOPA, and it is clear from the result in Fig. 5 that the system of tyrosine also contributes to the increase of indophenol reducing value when the lag period is sufficiently given to the system.

\section{DISCUSSION}

As mentioned above, the remarkable increase of indophenol reducing value was obtained when the mixture of DOPA, tyrosine and polyphenol oxidase was heated. Any substance which brings the increase of indophenol reducing value by heating is not known in the system of DOPA, tyrosine and polyphenol oxidase.

The melanin formation pathway from tyrosine and DOPA has been summarized by Mason $^{6}$ as shown in Fig. 8. The aqueous extract of potato tubers turns red by the action of polyphenol oxidase on tyrosine or 
DOPA. It is well known that the color is due to the formation of DOPAchrome. ${ }^{\text {ral }}$ The extract immediately turns from red to colorless by heating and simultaneously the indophenol reducing value increases. This is quite same as in the model system containing DOPA, tyrosine and the oxidase. According to Raper, ${ }^{7,10>}$ 5,6-dihydroxyindole was formed when the red solution obtained from tyrosine or DOPA by the action of polyphenol oxidase was allowed to decolorize by boiling or in racuo. 5,6-Dihydroxyindole is an intermediate in the melanin formation process and is a sort of reductone, though its indophenol reducing activity is not determined. The nature of synthesized 5,6-dihydroxyindole will be reported in a subsequent publication.

It is assumed from these results and some information reviewed above that the indo- phenol reducing substance is 5,6-dihydroxyindole derived from DOPAchrome.

Acknowledgement. The author wishes to thank Profs. D. Nomura and H. Oomura, Kyushu University, for their helpful guidance.

\section{REFERENCES}

1) S. Numa and D. Nomura, Nippon Nogeikagaku Kaishi, 43, 837 (1969).

2) S. Numa, ibid., 45, 216 (1971).

3) H. von Euler and H. Hasselquist, Arkiv. Kemi., 8, 67 (1955).

4) L. E. Arnow, J. Biol. Chem., 118, 531 (1937).

5) F. Kubowitz, Biochem. Z., 299, 32 (1938).

6) H.S. Mason, Advances in Enzymology, 16, 105 (1955).

7) H. S. Raper, Biochem. J., 21, 89 (1927).

8) Idem, J. Chem. Soc., 1938, 125.

9) H. S. Mason, J. Biol. Chem., 172, 83 (1948);

10) H. S. Raper, Biochem. J., 20, 735 (1926). 